\title{
The Seasonal Cycle and Interannual Variability in Stratospheric Temperatures and Links to the Brewer-Dobson Circulation: An Analysis of MSU and SSU Data
}

\author{
PAUL J. YOUNG \\ Cooperative Institute for Research in the Environmental Sciences, University of Colorado, and National Oceanic \\ and Atmospheric Administration, Boulder, Colorado \\ DAVID W. J. THOMPSON \\ Colorado State University, Fort Collins, Colorado \\ KAREN H. ROSENLOF \\ National Oceanic and Atmospheric Administration, Boulder, Colorado \\ SUSAN SOLOMON \\ National Oceanic and Atmospheric Administration, and Department of Atmospheric \\ and Oceanic Sciences, University of Colorado, Boulder, Colorado \\ JEAN-FRANÇOIS LAMARQUE \\ National Center for Atmospheric Research, ${ }^{*}$ Boulder, Colorado
}

(Manuscript received 10 December 2010, in final form 21 June 2011)

\begin{abstract}
Previous studies have shown that lower-stratosphere temperatures display a near-perfect cancellation between tropical and extratropical latitudes on both annual and interannual time scales. The out-of-phase relationship between tropical and high-latitude lower-stratospheric temperatures is a consequence of variability in the strength of the Brewer-Dobson circulation (BDC). In this study, the signal of the BDC in stratospheric temperature variability is examined throughout the depth of the stratosphere using data from the Stratospheric Sounding Unit (SSU).

While the BDC has a seemingly modest signal in the annual cycle in zonal-mean temperatures in the mid- and upper stratosphere, it has a pronounced signal in the month-to-month and interannual variability. Tropical and extratropical temperatures are significantly negatively correlated in all SSU channels on interannual time scales, suggesting that variations in wave driving are a major factor controlling globalscale temperature variability not only in the lower stratosphere (as shown in previous studies), but also in the mid- and upper stratosphere. The out-of-phase relationship between tropical and high latitudes peaks at all levels during the cold-season months: December-March in the Northern Hemisphere and July-October in the Southern Hemisphere. In the upper stratosphere, the out-of-phase relationship with high-latitude temperatures extends beyond the tropics and well into the extratropics of the opposite hemisphere.

The seasonal cycle in stratospheric temperatures follows the annual march of insolation at all levels and latitudes except in the mid- to upper tropical stratosphere, where it is dominated by the semiannual oscillation. Midto upper-stratospheric temperatures also exhibit a distinct but small semiannual cycle at extratropical latitudes.
\end{abstract}

* The National Center for Atmospheric Research is sponsored by the National Science Foundation.

Corresponding author address: Paul Young, NOAA/ESRL, 325 Broadway R/CSD8, Boulder, CO 80305.

E-mail: paul.j.young@noaa.gov

DOI: 10.1175/JCLI-D-10-05028.1 


\section{Introduction}

It has long been known that dynamical processes can drive stratospheric temperatures away from their radiative equilibrium value (e.g., Murgatroyd and Goody 1958). A particularly striking example is that the observed upper-stratosphere wintertime polar temperatures can exceed their estimated radiative equilibrium values by as much as $40 \mathrm{~K}$ (Fels 1985) or by more than $100 \mathrm{~K}$ (Shine 1987), depending on the radiation model used to estimate the equilibrium temperatures. On the global scale, the dominant dynamical feature that influences the zonally averaged distribution of temperature in the stratosphere is the Brewer-Dobson circulation (BDC), the wave-driven, Lagrangian-mean, meridional mass circulation linking the tropics to the higher latitudes (Dunkerton 1978). As reviewed by Birner and Bönisch (2011), the BDC can be thought of as consisting of a shallow branch, driven by synoptic and planetary waves breaking in the lower stratosphere (e.g., Plumb 2002; Randel et al. 2008), juxtaposed on a deep branch driven by planetary waves breaking in the mid- and upper stratosphere (e.g., Holton et al. 1995). The deep branch consists of one cell with downwelling into the winter hemisphere, and two cells during the spring and fall seasons (Birner and Bönisch 2011).

Understanding the observed variability of the BDC throughout the depth of the stratosphere is of interest for a range of climatic processes. The BDC plays a key role in determining the global-scale structure of the stratospheric flow and in stratospheric transport. It is also projected to accelerate in global chemistry-climate models forced by increased greenhouse gas concentrations (Butchart et al. 2010), although observational evidence of such strengthening is not definitive (see introduction of Ray et al. 2010). Previous studies have examined in detail the seasonal cycle and interannual variability in lower stratospheric temperatures and their linkages to dynamical variability in the BDC using data from the Microwave Sounding Unit (MSU) channel 4 (MSU-4; Yulaeva et al. (1994, hereafter YHW94; Ueyama and Wallace 2010). Here we exploit monthly-mean temperature data from the Stratospheric Sounding Unit (SSU) to extend such analyses throughout the depth of the stratosphere. This allows the use of previously used diagnostics to explore variations in the deep branch of the BDC.

The general mechanics of the BDC are reviewed by Holton et al. (1995) and are based on the "downward control" principle (Haynes et al. 1991). The basic idea is that wave breaking in the stratosphere exerts an easterly body force that, in turn, induces a poleward mass flux. By mass conservation, below the altitude of the forcing the poleward mass flux is accompanied by upwelling (and expansional cooling) at low latitudes, and subsidence (and compressional heating) at high latitudes. In the long-term mean, the easterly body force is balanced by the Coriolis torque acting on the poleward mass flux, and the regions of mean upwelling and downwelling are limited to the region below the forcing, hence the phrase downward control. The latitudinal location of the relevant wave breaking that drives the tropical upwelling is still open to debate (see Fueglistaler et al. 2009; Ueyama and Wallace 2010).

The conditions for vertical planetary wave propagation into the stratosphere are most favorable during the Northern Hemisphere (NH) winter and Southern Hemisphere (SH) spring, when the stratospheric flow is westerly but not too strong to inhibit wave propagation (Charney and Drazin 1961). The amplitude of the wave breaking and thus the BDC are largest in the $\mathrm{NH}$, where planetary waves are more efficiently forced by the orography and land-sea temperature contrasts (e.g., Hirota et al. 1983; Shiotani and Hirota 1985; Holton et al. 1995). The hemispheric imbalance in the strength of the BDC is consistent with a tropical upward mass flux that is twice as strong in the $\mathrm{NH}$ winter than it is in the SH winter (Rosenlof and Holton 1993; Rosenlof 1995). It is thus also consistent with the observed January-February temperature minimum in the tropical lower stratosphere (Reed and Vlcek 1969; YHW94), which has important implications for the annual cycle in the stratospheric entry value of water vapor (Mote et al. 1996). In the summer hemisphere, vertical Rossby wave propagation is impeded by easterly winds above $\sim 50 \mathrm{hPa}$, but a shallower and weaker meridional overturning cell develops in the lower stratosphere (Rosenlof 1995). The summertime circulation cell is more vigorous in the $\mathrm{SH}$, consistent with stronger gravity wave driving there (Alexander and Rosenlof 1996; Rosenlof 1996).

The relationship between vertical motion due to the BDC and stratospheric temperature can be interpreted through a linearized version of the transformed Eulerian mean (TEM) thermodynamic energy equation (e.g., Andrews et al. 1987):

$$
\frac{\partial \bar{T}}{\partial t}=-a_{r}\left(\bar{T}-T_{r}\right)-\bar{w}^{*} S
$$

where $\partial \bar{T} / \partial t$ is the local temperature tendency; $\alpha_{r}(\bar{T}-$ $T_{r}$ ) denotes the relaxation of the temperature to a radiative equilibrium value $T_{r}$, with a time scale of $1 / \alpha_{r} ; \bar{w}^{*} / S$ denotes the adiabatic cooling (heating) tendency, associated with upward (downward) residual vertical velocity $\bar{w}^{*}$ and a static stability parameter $S$; and the overbars denote the zonal mean. Equation (1) states that in the zonal average, the local temperature change 
is approximately balanced by a combination of diabatic (predominantly radiative in the stratosphere) and adiabatic processes (e.g., Garcia 1987).

The first evidence for a robust link between the annual cycle in tropical lower stratosphere temperature and residual vertical velocity was provided by YHW94. YHW94 suggested that the annual cycle of the tropical lowerstratosphere temperatures reflects the seasonal cycle in the strength of extratropical wave driving. They argued that the strong degree of compensation between the annual temperature cycle in the tropical and extratropical lower stratosphere is due to the BDC. They further noted that vertical motion has no effect on globally averaged temperatures (assuming the static stability and radiative relaxation times are constant at a fixed level) and thus that diabatic processes dominate the annual cycle in global-mean stratospheric temperatures. Support for their interpretation was provided by Rosenlof (1995), who showed that for the tropical lower stratosphere, the seasonal cycle of the temperature tendency in Eq. (1) is dominated by the seasonal cycle in the adiabatic term. However, Fueglistaler et al. (2011) have recently suggested that the strong degree of compensation between tropical and extratropical stratospheric temperatures in the annual cycle of lower-stratospheric temperatures is an artifact of the MSU-4 weighting function. They argue that both the static stability and radiative time scales exhibit latitudinal structure, and thus that the temperature changes associated with vertical motions in the lower stratosphere do not necessarily cancel in the global mean.

The present study examines seasonal and interannual variability in the BDC as inferred from temperature measurements from both the MSU and SSU instruments. The SSU data have been used extensively for examining trends in stratospheric temperatures (e.g., see Randel et al. 2009), but less so for examining seasonal and interannual variability in temperatures in a manner complementary to the analyses in YHW94. In addition, key climatological features of the MSU and SSU data, previously documented from other sources, are described. Section 2 describes the MSU and SSU data. Section 3 examines the annual cycle of MSU and SSU temperatures as a function of latitude and height. Section 4 probes interannual variability in tropical and high-latitude temperatures in the mid- and upper stratosphere. The main conclusions are presented in section 5 .

\section{Satellite temperature data}

Monthly-mean brightness temperature datasets for 1979-2005 are from the lower-stratospheric retrieval of the MSU instrument (MSU-TLS), a combination of

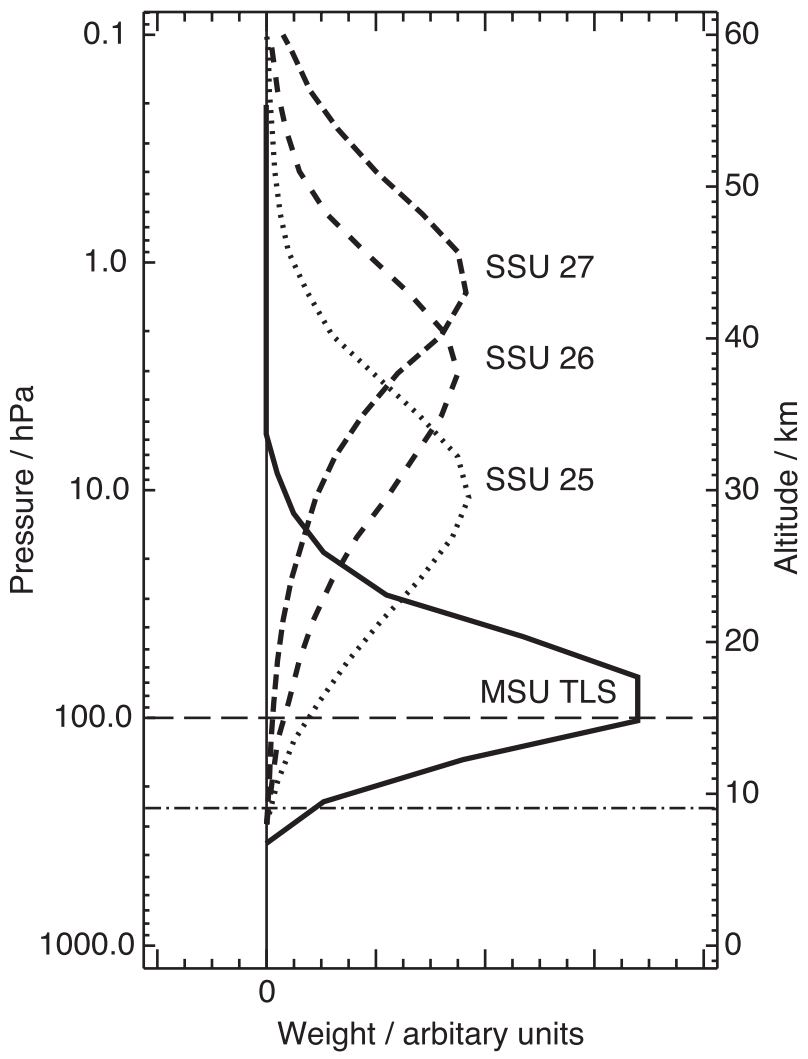

FIG. 1. Weighting functions for the MSU-TLS and SSU-25, -26, and -27 channels used in this analysis (after Randel et al. 2009). The dash and dash-dot lines give indicate the approximate position of the tropical and high-latitude tropopause, respectively.

channel 4 from MSU and channel 9 from the Advanced MSU (AMSU), and the mid- and upper-stratospheric channels for the SSU instrument (SSU-25, -26, and -27). Note that the AMSU instrument is the only one providing data beyond 2005. Figure 1 illustrates the weighting functions for these channels.

The weighting functions of the $3 \mathrm{SSU}$ channels used in this study, SSU-25, -26 , and -27 , have peak sensitivities at approximately 10,3 , and $1.5 \mathrm{hPa}[\sim(30,38$, and 42$) \mathrm{km}]$, respectively. The half-power widths of these channels are approximately $3-45 \mathrm{hPa}(20-38 \mathrm{~km}), 20-1 \mathrm{hPa}$ (28-46 km), and 5-0.5 hPa (35-52 km). Thus, SSU-25 samples primarily the midstratosphere while SSU-26 and -27 sample both the mid- and upper stratosphere. Figure 1 also shows that MSU-TLS senses with at least half-power sensitivity over the approximate range of 150$40 \mathrm{hPa}(13-22 \mathrm{~km})$. The lower-altitude end of this range is close to the level of the tropical tropopause, although the channel is sensing only the stratosphere at higher latitudes.

The SSU data were provided by the National Oceanic and Atmospheric Administration (NOAA) Climate 
Prediction Center (C. Long and R. Lin 2009, personal communication). They consist of monthly and zonal means, spanning $70^{\circ} \mathrm{S}-70^{\circ} \mathrm{N}$ with a resolution of $10^{\circ}$, and have been used in the most recent stratospheric trend synthesis study (Randel et al. 2009). The MSU-TLS data are version 3.2 from the Remote Systems Sensing retrieval of the MSU/AMSU channels (Mears and Wentz 2009). The data have a resolution of $2.5^{\circ}$ in latitude, spanning $82.5^{\circ} \mathrm{S}-82.5^{\circ} \mathrm{N}$.

The uncertainties inherent in the MSU and SSU instruments have been summarized elsewhere (e.g., Brindley et al. 1999; Shine et al. 2008; Randel et al. 2009 and references therein) and are primarily relevant for trend analyses, which are not conducted here.

\section{Annual cycle}

This section summarizes the seasonal cycle in stratospheric temperatures from MSU and SSU data as a function of latitude and altitude for the tropics, extratropics, and global mean.

\section{a. Zonal-mean temperatures}

\section{1) Horizontal AND VERTICAL STRUCTURE}

Figure 2 shows the annual cycle of zonal-mean, climatological-mean temperatures derived from the MSU-TLS and SSU-25, -26, and -27 data. The seasonal cycle is repeated in all panels. At mid- and high latitudes, the annual cycle is dominated by the south-north march of maximum insolation during the calendar year. The amplitude of the annual cycle is largest at polar latitudes, and in general temperatures increase monotonically with height, consistent with increasing ozone concentrations and the resultant shortwave heating.

Wintertime conditions generally persist longer in the lower stratosphere than they do in the upper stratosphere (see also Labitzke 1974), consistent with the downward propagation of the seasonal breakdown of the stratospheric polar vortex (e.g., Hartmann 1976; Hirota et al. 1983; Randel 1988). The September-October reversal in the latitudinal temperature gradient at $50^{\circ} \mathrm{S}$ in the SSU27 data (and somewhat less so in the SSU-26 data) is consistent with what Hitchman et al. (1989) referred to as the "separated stratopause warm anomaly." They noted that the winter polar stratopause is determined by a local temperature maximum that descends from the mesosphere $(\sim 60 \mathrm{~km})$ to $\sim 45 \mathrm{~km}$ in the months following the solstice. The temperature maximum is itself a consequence of gravity wave-induced downwelling, which is focused on the Pole (Leovy 1964) and is stronger and more robust in the SH (Hitchman et al. 1989; although note that a relatively weak $\mathrm{NH}$ temperature maximum is evident in the SSU-27 and -26 data during February at $\sim 60^{\circ} \mathrm{N}$ ). Other studies have discussed the gradient reversal as a signature of strong high-latitude wave activity in the upper stratosphere during the winter-spring transition (Hirota et al. 1983; Shiotani and Hirota 1985; Randel 1988).

Figure 2 also reveals hemispheric differences in the seasonal cycle. The amplitude of the annual cycle is greatest in the $\mathrm{SH}$ at all levels, which experiences colder winter temperatures and warmer summer temperatures compared to the NH throughout the depth of the stratosphere, as noted in the seminal works of Fritz and Soules (1970) and Barnett (1974). Indeed, for each satellite channel the coldest temperatures are found over the SH polar regions during austral winter.

Throughout the stratosphere, the fact that wintertime temperatures are colder in the $\mathrm{SH}$ compared to the $\mathrm{NH}$ can be traced to a mixture of dynamics (e.g., Shiotani and Hirota 1985; YHW94), the seasonal cycle of solar irradiance (due to the eccentricity of the earth's orbit; e.g., Barnett 1974), and the direct radiative impact of the cold Antarctic plateau (Francis and Salby 2001). In the lower stratosphere, warmer NH polar winter temperatures are a consequence of enhanced downwelling related to in the seasonal cycle in the BDC (YHW94): for example, high-latitude $\mathrm{SH}$ and $\mathrm{NH}$ winter temperatures are around 185 and $204 \mathrm{~K}$, respectively, or 5 and $\sim 25 \mathrm{~K}$ greater than the 70 -hPa approximate radiative equilibrium value of $180 \mathrm{~K}$ calculated by Shine (1987, his Fig. $7 b$ ), at $82.5^{\circ}$ latitude.

The hemispheric asymmetry in extratropical wintertime temperatures in the upper SSU channels suggests that the seasonal cycle in the BDC extends well into the upper stratosphere, albeit with weaker influence than in the lower stratosphere. For example, the difference between the June-August (JJA) average SH high-latitude $\left(>60^{\circ} \mathrm{S}\right)$ and December-February (DJF) average NH highlatitude $\left(>60^{\circ} \mathrm{N}\right)$ temperatures decreases from $\sim 14 \mathrm{~K}$ in the lower stratosphere (MSU-TLS) to $2.7 \mathrm{~K}$ for the upper stratosphere (SSU-27). The smaller hemispheric differences in the upper stratosphere may be related to 1) the smaller hemispheric asymmetries in the BDC in the upper stratosphere; 2) the shorter radiative relaxation time scales in the upper stratosphere relative to the lower stratosphere (e.g., Shine 1987); or 3) the compensating effects of downwelling from mesospheric gravity wave breaking, which Garcia and Boville (1994) found is more important in the $\mathrm{SH}$ than it is in the $\mathrm{NH}$. The results in Fig. 2 differ somewhat from those reported by Kanzawa (1989), who found that Antarctic winter temperatures are warmer than the Arctic winter temperatures at the stratopause at $80^{\circ}$ latitude. The discrepancy between Fig. 2 and Kanzawa's findings is likely due to sampling (the SSU data do not extend poleward of $70^{\circ} \mathrm{N}$ ), or the 

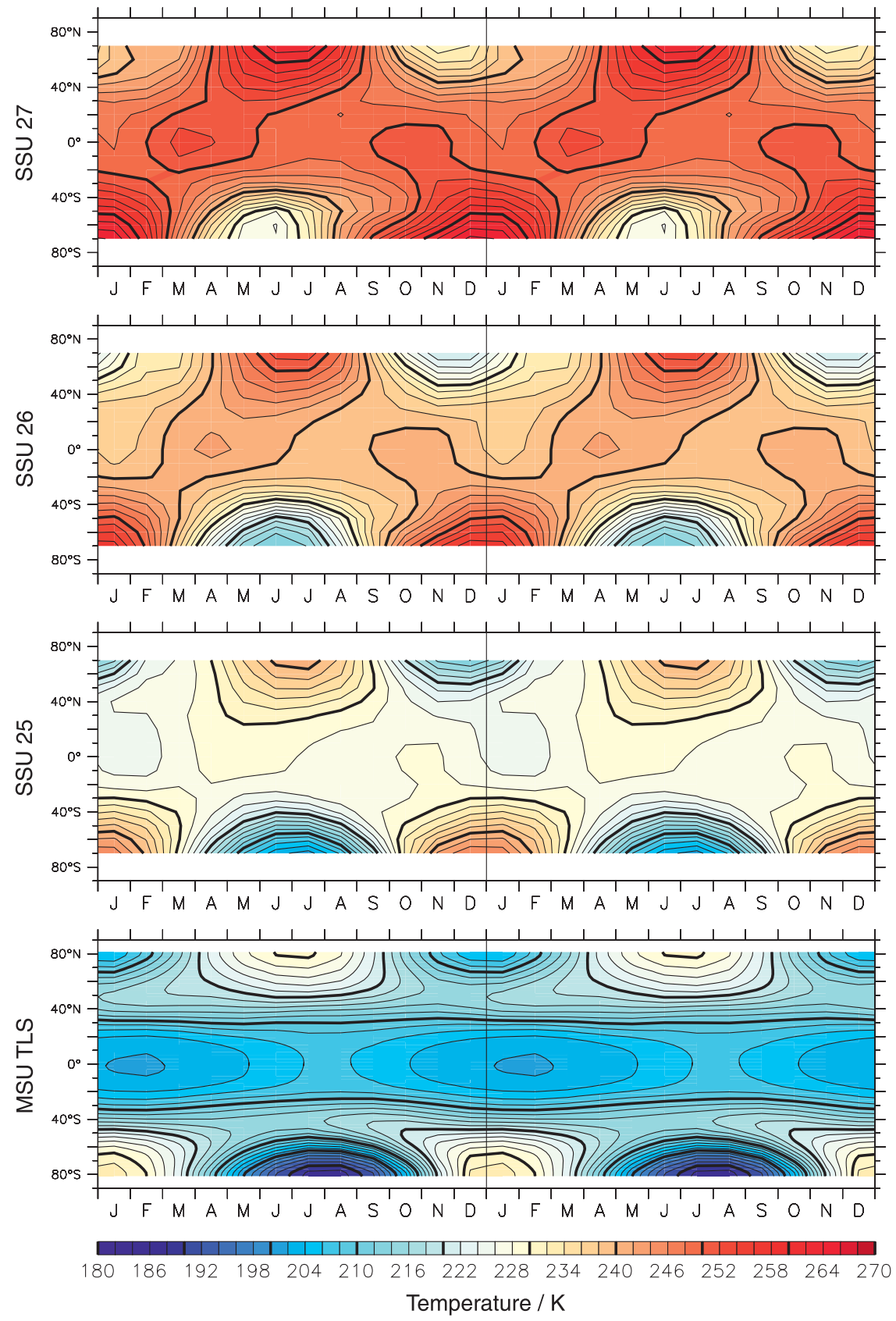

FIG. 2. Latitude-month climatological annual cycle of temperature for (bottom to top) the MSU-TLS and SSU-25, -26, and -27 data. The contour interval is $2 \mathrm{~K}$, with every $10 \mathrm{~K}$ highlighted by thicker lines. Two complete cycles are shown.

different weighting functions applied to the SSU-27 data and the Nimbus satellite data used in his study.

The hemispheric asymmetry in the seasonal cycle of stratospheric temperatures is also observed during the summer seasons: $\mathrm{SH}$ temperatures are $\sim(3-3.5) \mathrm{K}$ warmer than $\mathrm{NH}$ temperatures during their respective summers. Model integrations by Siskind et al. (2003) suggest that, in the lower stratosphere, this asymmetry is driven by stronger summertime gravity wave forcing in the $\mathrm{SH}$ compared to $\mathrm{NH}$, leading to increased downwelling and higher temperatures through compressional heating. Orbital eccentricity may also play a role down to $20 \mathrm{~km}$ (Siskind et al. 2003).

Tropical temperatures are notably colder in the MSUTLS data compared to all SSU levels. In fact, the lower tropical stratosphere is the coldest region in Fig. 2 
except for the lower-stratospheric SH high latitudes during austral winter. The minimum MSU-TLS tropical temperature is experienced during January-February and the maximum is experienced during July-August. These features have been noted previously by Reed and Vlcek (1969) and YHW94. The subject of the annual cycle in tropical temperatures will be revisited in sections $3 \mathrm{~b}$ and $4 \mathrm{c}$. Below we analyze the semiannual component of the seasonal cycle in the temperature data.

\section{2) The Semiannual Oscillation}

In the tropics, the annual march of temperatures differs greatly from the lower stratosphere (MSU-TLS) to the mid- and upper stratosphere (SSU). Moving from SSU-25 to -27, it is clear that tropical temperatures become increasingly dominated by the stratospheric tropical Semiannual Oscillation (SAO). The stratospheric SAO is characterized by westerly zonal winds at the solstices and easterly zonal winds at the equinoxes (Hirota 1978; Garcia et al. 1997). The SAO in temperature follows from thermal wind balance and a secondary meridional circulation, with ascent and cooling at the equator in the easterly phase, and descent and warming in the westerly phase (Andrews et al. 1987). The amplitude of the SAO is largest in December-May, which is thought to be a consequence of hemispheric asymmetries in wave driving (Delisi and Dunkerton 1988; Garcia et al. 1997). The key features of the SAO are apparent in the SSU-26 and -27 data, with peak tropical temperatures in March-April and October-November, and the March-April peak exceeding that of the October-November peak by $\sim 1 \mathrm{~K}$ for SSU-26 and $1.5 \mathrm{~K}$ for SSU-27. The SAO is less apparent in the SSU-25 data.

Figure 3 summarizes the characteristics of the SAO in the temperature data in more detail. The left panels show as a function of latitude the amplitude of the SAO (black) and the amplitude normalized by the amplitude of the annual cycle (at the given latitude, red); the right panels show as a function of latitude and month the timing (or phase) of the maximum value of the SAO. The analyses were performed by fitting annual and semiannual cosine/sine harmonics to the data as a function of latitude.

The amplitude of the tropical SAO is largest at the levels sampled by SSU-26 and -27, where it peaks at the equator and decays toward the Pole (see also Randel et al. 2004). While the absolute amplitude of the SAO is approximately symmetric about the equator (Fig. 3a, black lines), the amplitudes relative to the annual cycle (Fig. 3a, red lines) are skewed to the SH tropics for SSU-25 and -26, consistent with the analysis of Delisi and Dunkerton (1988). At the equator, the timing of the maximum temperature in the SAO occurs later in the year at lower altitudes. The amplitude of the tropical SAO in the MSU-TLS data is very small. At levels above SSU-25, the amplitude of the SAO increases again at polar latitudes (Fig. 3a, black lines), but has little amplitude there relative to the annual cycle (Fig. 3a, red lines; Fig. 3b, red dots). The amplitude of the SAO at high latitudes is only around $20 \%-30 \%$ that of the annual cycle, compared to $250 \%-350 \%$ for the tropical SAO at the SSU altitudes (red lines in the left panels; see also van Loon et al. 1972). Note that the depth of the weighting functions means that each individual satellite channel is sensing different phases and amplitudes of the SAO, giving a coarser picture than that provided by rocketsondes (e.g., Hirota 1978).

Explanations for the high-latitude SAO include 1) the superposition of the annual cycle and episodic wavedriven variability in the extratropical vortex (Hirota 1980; Hirota et al. 1983; Gao et al. 1987; Randel 1988); 2) a semiannual component to the ozone seasonal cycle (Perliski and London 1989; Perliski et al. 1989); and 3) the descending separated stratopause warm anomaly (Hitchman et al. 1989). The existence of an SAO in the MSU-TLS data at SH high latitudes is consistent with the onset of ozone depletion and attendant decrease in temperatures during spring (e.g., Solomon 1999), which give rise to a second harmonic in temperatures (note the SAO at $90^{\circ} \mathrm{S}$ peaks around January and thus has a minimum around October).

\section{b. Global-, tropical-, and extratropical-mean temperatures}

The analysis below considers the annual cycles averaged over different latitudinal bands. For consistency with YHW94, we shall consider the annual cycle in temperature for the tropical $\left(30^{\circ} \mathrm{S}-30^{\circ} \mathrm{N}\right)$, extratropical (poleward of $30^{\circ}$; averaged over both hemispheres) and global cosine-weighted averages, as derived from the 1979-2005 time series of the MSU and SSU data (recall that the SSU data only extends to $70^{\circ}$ in both hemispheres). These latitude bands are such that the tropics and extratropics each represent approximately half of the global surface area, although it is important to note that this definition of the tropics likely includes regions of downwelling at certain times of the year (Rosenlof 1995; see below also).

Figure 4 shows the seasonal march of stratospheric temperature for the above latitude bands. The shading about the lines indicates \pm 1 temporal standard deviations based on the 1979-2005 series; interannual variability is discussed further in section 4 . Note that the vertical axis scale is different on each panel. 
(a) Amplitude of SAO
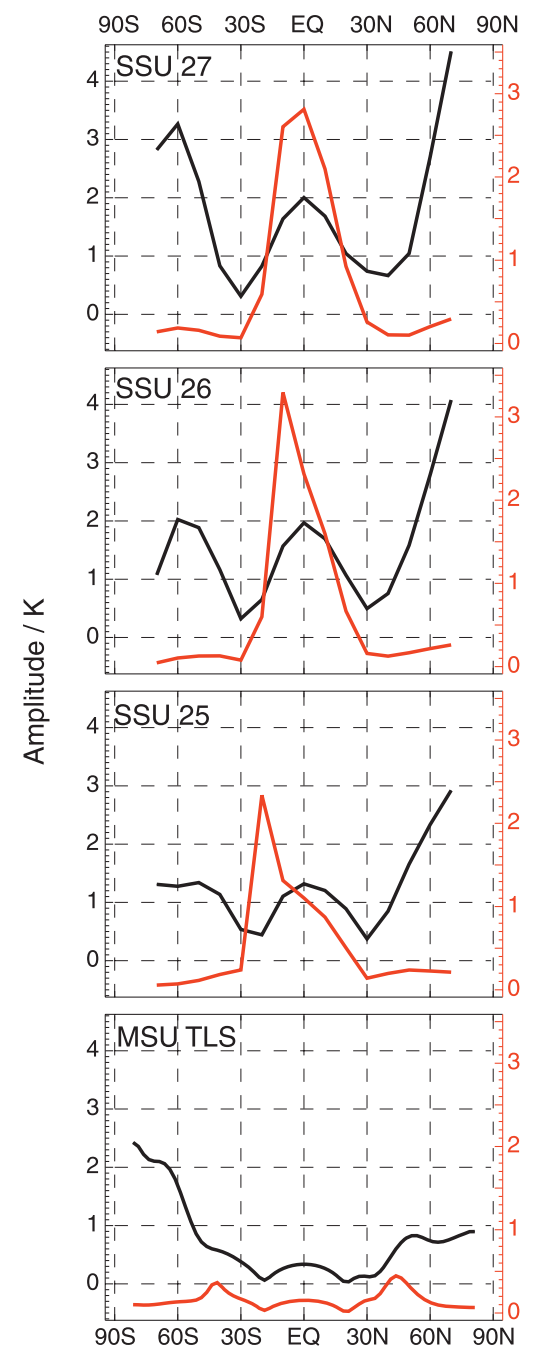

(b) Months of SAO maximum

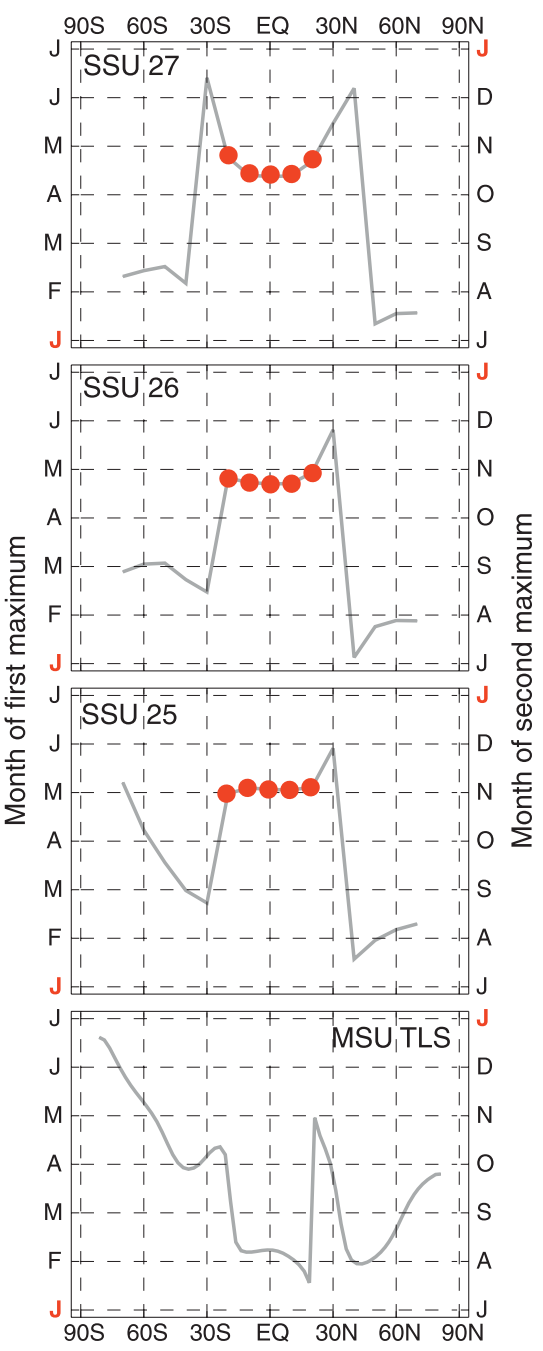

FIG. 3. (bottom to top) Harmonic analysis of SAO in the MSU-TLS and SSU-25, -26, and -27 data, by latitude. (a) Left-hand axis shows amplitude of the SAO (black) and right-hand axis is amplitude of SAO divided by amplitude of annual cycle at that particular latitude (red). (b) Months of maximum temperature in the SAO with January as a red J. Red dots highlight where the SAO amplitude is at least $50 \%$ of the annual cycle amplitude. Left-hand axis shows first maximum; right-hand axis shows the second. Note that the month names on the $y$ axes correspond to the start of the month.

For MSU-TLS, Fig. 4 gives the same pattern as reported by YHW94. The extratropical temperature is at a minimum in austral winter (July-August), which coincides with the maximum in the tropical temperature. As the annual cycle in both regions is close to sinusoidal, with approximately the same amplitude, the resulting globally averaged temperature is almost constant throughout the year. YHW94 interpreted the out-of-phase seasonal cycles in tropical and extratropical lower-stratospheric temperatures as resulting from the hemispheric difference in wave driving during winter. Fueglistaler et al. (2011) have questioned whether the near-perfect cancellation of the tropical and extratropical temperatures is an artifact of the MSU-TLS weighting function, but they agree that the seasonal cycle of the BDC plays a role in the annual march of temperatures.

In the mid- and upper stratosphere, the BDC has a weaker signature in the long-term mean annual cycle. Extratropical temperatures are colder than their tropical counterparts during much of the year except for the middle of $\mathrm{NH}$ winter. The out-of-phase relationship between tropical and extratropical temperatures is less robust than it is in the lower stratosphere, and thus the seasonal cycle in globally averaged temperatures is more pronounced 

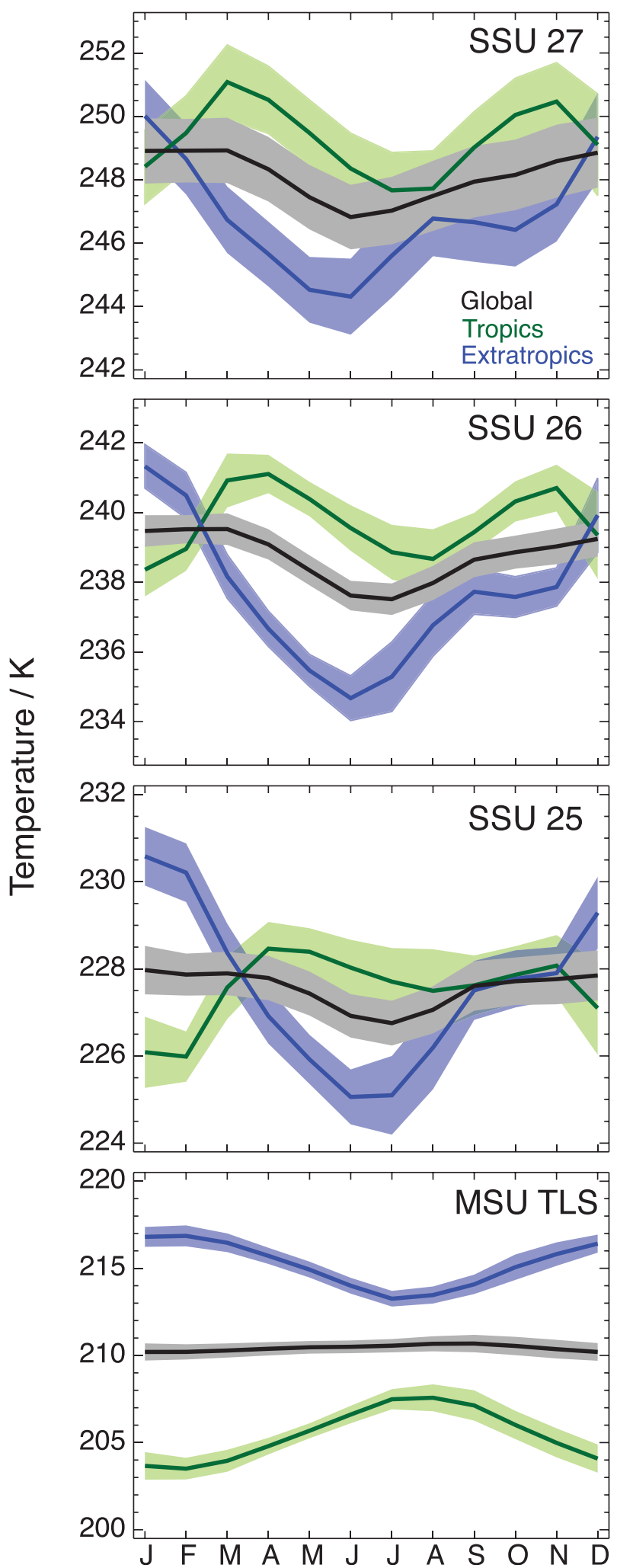

FIG. 4. Climatological annual cycle of global (full extent of data, black), tropical $\left(30^{\circ} \mathrm{S}-30^{\circ} \mathrm{N}\right.$, green) and extratropical (poleward of $30^{\circ}$, blue) average temperatures for (bottom to top) MSU-TLS and SSU-25, -26 , and -27 data. The shaded areas about the lines denote \pm 1 temporal standard deviation. Note the different scales on the $y$ axis. in the mid-upper stratosphere (Fig. 4). Moving from SSU-25 to -27 the stratospheric SAO becomes increasingly apparent in tropical temperatures, as discussed in the previous section. In the SSU-25 and -26 data, tropical temperatures are significantly lower than extratropical temperatures only during $\mathrm{NH}$ winter and early spring, which suggest that the influence of the BDC peaks during these seasons.

Figure 4 shows that the annual cycle of extratropical temperatures for the SSU channels is also not as sinusoidal as for the MSU-TLS data. In fact, in SSU-26 and -27 there are two distinct minima in extratropical temperatures: the largest minimum occurs around JuneJuly in the SSU data (in contrast to July-August for MSU-TLS) and a secondary smaller minimum occurs around September-November. The June-July minimum is consistent with the signal of the less dynamically disturbed SH vortex in the extratropical average. The origin of the secondary minimum in extratropical temperatures centered around November is less obvious, although it could be related to dynamically generated temperature changes associated with the residual circulation cell induced by the tropical SAO (Hitchman and Leovy 1986).

Figure 5 superposes the global-mean temperature seasonal cycles from Fig. 4 on the annual-mean time series of the Sun-Earth distance and tropical column ozone. Again, note the different ranges on the vertical axis for the individual panels. The range of the global-mean temperatures grows monotonically with altitude from $0.5 \mathrm{~K}$ in the lower stratosphere to $2.25 \mathrm{~K}$ in the upper stratosphere. As also evidenced in Fig. 4, the global minimum temperature occurs during December-February for MSUTLS and June-July for the SSU data.

YHW94 proposed that when Eq. (1) is integrated globally the adiabatic term vanishes, meaning that diabatic processes must drive any resultant seasonal cycle of temperature. This interpretation assumes that the static stability and radiative time scale can be treated as constant globally, which Fueglistaler et al. (2011) show is not the case. Nevertheless, YHW94 showed that the global seasonal cycle of lower-stratosphere temperatures was consistent with the seasonal variation of stratospheric tropical ozone (i.e., temperatures are correlated with shortwave heating by ozone). Figure 4 suggests that the small global temperature cycle is driven by "excess heating" in the tropics.

The bottom panel in Fig. 5 confirms the correspondence between column ozone and global-mean temperatures in the lower stratosphere in the longer dataset afforded by this study. The column is derived from a $30^{\circ} \mathrm{S}-30^{\circ} \mathrm{N}$ average of a 1979-2005 climatology from a recent solar backscatter ultraviolet (SBUV) ozone dataset (McLinden et al.2009), and the partial column is the sum of the SBUV 


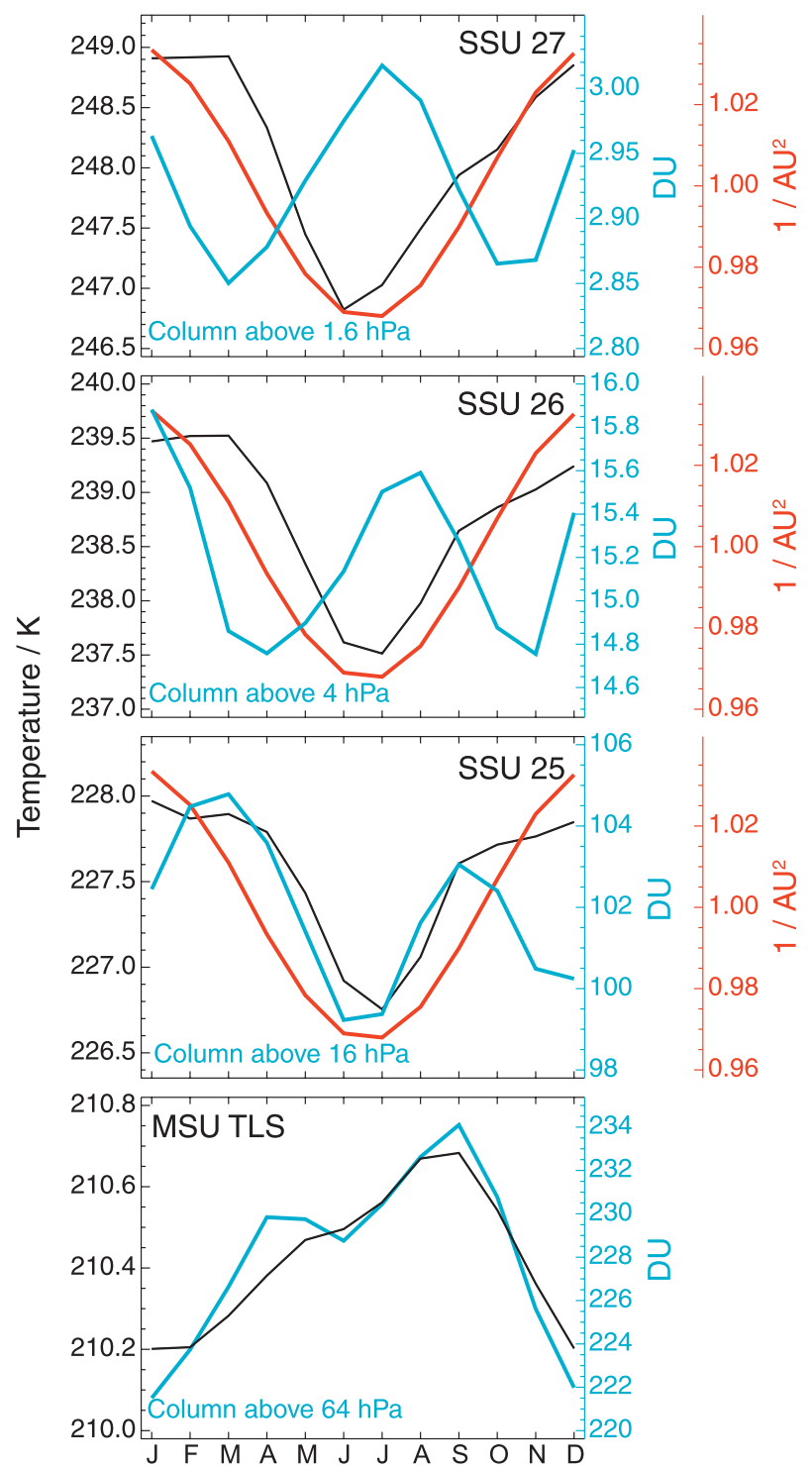

FIG. 5. Expansion of climatological annual cycle of global average temperatures in Fig. 4 (black, left-hand axis) with the tropical $\left(30^{\circ} \mathrm{S}-30^{\circ} \mathrm{N}\right)$ partial ozone column above the given level [Dobson units (DU)] also plotted (blue, right-hand axis), as derived from SBUV data (see text). For (bottom to top) the SSU-25, -26, and -27 data, the second right-hand axis (red) depicts the annual cycle of the Earth-Sun distance in astronomical units (AU).

layers above $64 \mathrm{hPa}$. This represents the ozone above the MSU-TLS layer, which might be expected to exert the largest control on the TLS temperatures. That the lowerstratosphere ozone concentration is minimum in January is itself a consequence of the stronger tropical upwelling in boreal winter-compared to austral winter-exporting more ozone-rich air and replenishing it with ozone-poor air from the tropical troposphere (Logan 1999; Randel et al. 2007). However, Fueglistaler et al. (2011) show that the determining the drivers of the global-mean annual cycle is not trivial, highlighting the aforementioned links between ozone and dynamics as a particularly complicating factor.

In contrast to the lower stratosphere, the general shape of the global temperature annual cycle for the SSU channels exhibits close correspondence with the annual cycle in solar irradiance driven by Earth's eccentric orbit around the Sun (as also reported by, e.g., Barnett 1974), and not with tropical or global (not shown) ozone amounts. This is especially true for the SSU-27 data, which is close to the level of maximum solar heating (Siskind et al. 2003). However, the correspondence is not perfect and a more detailed quantitative analysis (e.g., as per Siskind et al. 2003) is needed to ascertain the key physical drivers of the seasonal cycle in global temperatures in the mid- and upper stratosphere.

That the seasonal cycles of the tropical ozone columns appear as they do in the SSU-26 and -27 panels is due to the concentrations following the temperatures of the tropical SAO, as previously described by Ray et al. (1994). For SSU-25, the interpretation of the ozone column seasonal cycle is complicated by the fact that it spans both the lower and upper stratosphere.

\section{Interannual variability and the Brewer-Dobson circulation}

This section analyzes the interannual variability of the monthly-mean temperature data, concentrating on the seasonal patterns of the variability, the seasonal structure of the relationship between the high latitudes and tropics, and how both relate to the seasonal cycle of the BDC.

\section{a. Tropical and extratropical coupling on a month-to-month basis}

As well as exploiting the climatology of the MSU globally averaged data, YHW94 showed that the monthto-month temperature changes in the tropics $\left(30^{\circ} \mathrm{S}-\right.$ $30^{\circ} \mathrm{N}$ ) and extratropics (poleward of $30^{\circ} \mathrm{S}$ and $30^{\circ} \mathrm{N}$ ) are significantly anticorrelated, which they reasoned is indicative of the compensating compressional warming and expansional cooling of the temperatures in the two regions arising from the meridional circulation. A similar analysis is conducted here, extending up to the mid- and upper-stratospheric levels sensed by the SSU channels.

Figure 6 is a scatterplot showing the relationship of the month-to-month temperature anomalies in the tropics and extratropics for the MSU and SSU data. The temperature anomalies were calculated relative to the climatologicalmean annual cycle (1979-2005) and construction of the figure followed the analysis of the MSU data by YHW94 (their Fig. 3). The correlation coefficient $r$ for the tropical 

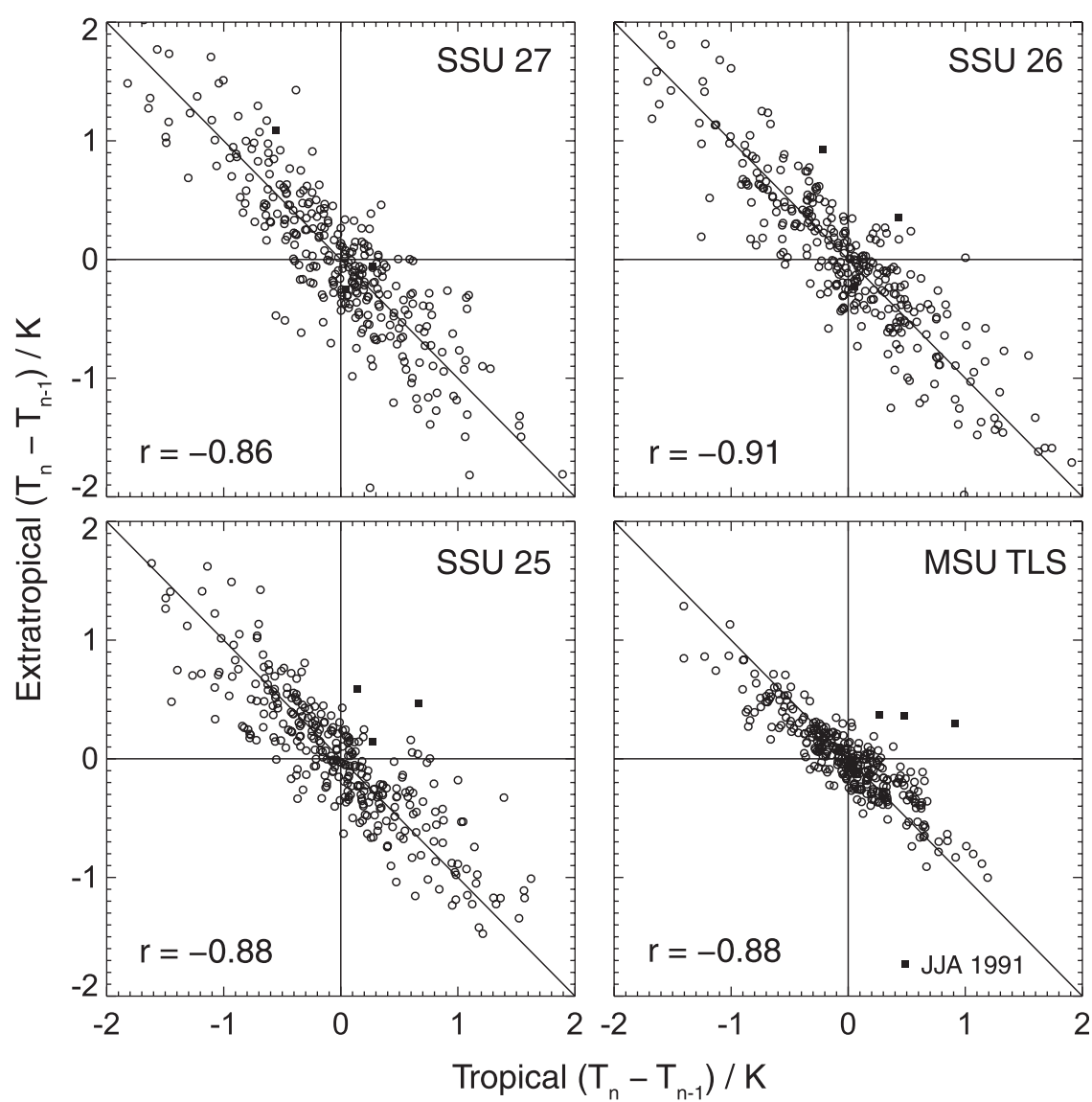

FIG. 6. Scatterplot of the month-to-month change in temperature anomalies (relative to the mean 1979-2005 annual cycle) for the tropics $\left(30^{\circ} \mathrm{S}-30^{\circ} \mathrm{N}\right)$ against those for the extratropics (poleward of $30^{\circ} \mathrm{S}$ and $30^{\circ} \mathrm{N}$ ) for the MSU-TLS and SSU-25, -26, and -27 data (1979-2005). The filled black squares denote $T_{n}=$ June, July, and August 1991, corresponding to the timing of the Mt. Pinatubo eruption. The correlation coefficient $r$ for the tropical vs extratropical temperature change is also given. The solid diagonal line through each is the $1:-1$ line, representing a perfect anticorrelation. The horizontal and vertical lines represent no change in the tropical and extratropical temperatures, respectively.

and extratropical temperatures is indicated on the bottom left of the panels, and the values are significant for all four channels.

The key result in Fig. 6 is that the strong negative correlations between tropical and extratropical temperatures extend well into the mid- and upper stratosphere. This result indicates that the influence of wave-driven variability in the BDC extends throughout the lower to upper stratosphere, extending the key conclusions of YHW94 regarding the MSU lower-stratospheric data.

The outliers associated with diabatic heating from sulfate aerosol following the eruption of Mt. Pinatubo (e.g., McCormick et al.1995) are limited to the MSU-TLS and SSU-25 data (solid squares in Fig. 6; as noted in YHW94 the eruption degrades the relationship between tropical and extratropical temperatures). Thus, Fig. 6 shows that the perturbation associated with the Pinatubo aerosol is largely confined to the lower stratosphere, in agreement with Randel et al. (2009). That the outliers are positioned in the top-right quadrant is consistent with the warming extending to latitudes outside of the tropics. Excluding periods influenced by Pinatubo results in a small increase in the strength of the anticorrelation.

\section{b. Interannual variability by latitude and month}

Figure 7 shows the temporal standard deviation of the MSU and SSU data as a function of latitude and month. To remove the influence of any trend on the variability, the data were detrended as a function of latitude and month prior to the calculation.

In the extratropics, maxima in the interannual variability of the temperatures are clearly evident for all the satellite channels in the $\mathrm{NH}$ from November to April and in the $\mathrm{SH}$ from June-November. The peaks in 

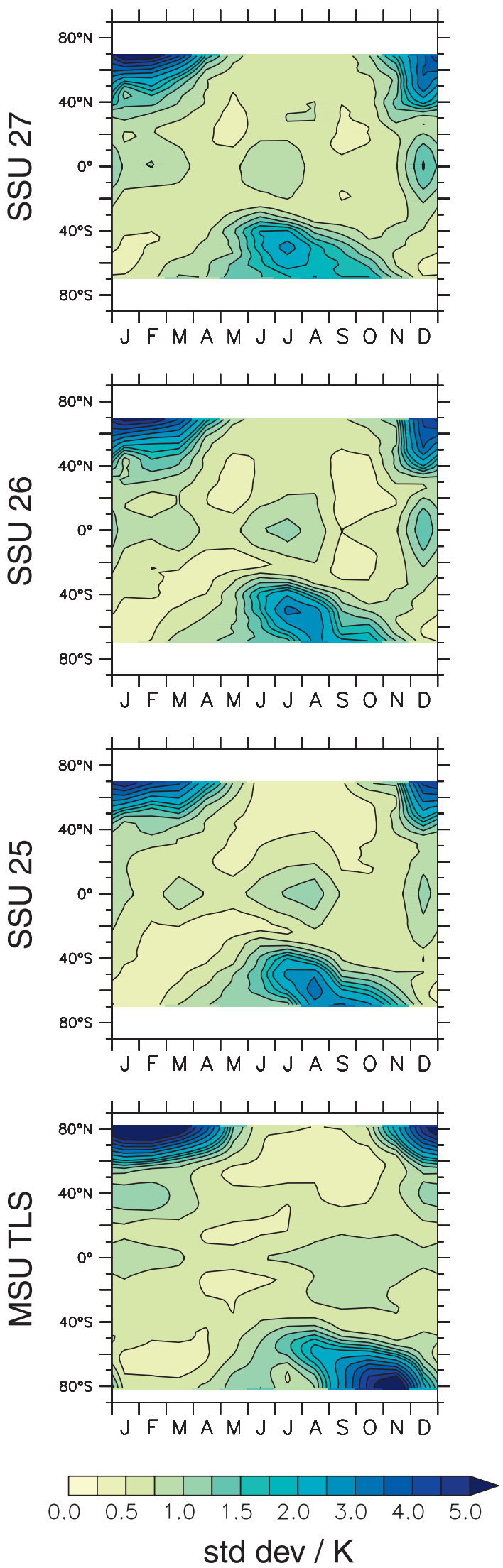

extratropical variance are coincident with the strongest wave activity in the respective hemispheres (e.g., Labitzke 1982; Shiotani and Hirota 1985; Scaife et al. 2000; Tegtmeier et al. 2008). In the tropics, the SSU data reveal maxima during the seasons of largest variability in the extratropics: around December in association with the $\mathrm{NH}$ variance maximum, and around July in association with the $\mathrm{SH}$ variance maximum. These tropical maxima are consistent with the influence of the large variability in the BDC wave driving (resulting in changes in the strength of the tropical upwelling), and are more comparable to the magnitude of the high-latitude values when the data are scaled by cosine of latitude (not shown). The maxima in tropical variability are less obvious in the MSU-TLS data.

Figure 7 reveals three key differences between the hemispheres: 1) the variance in wintertime temperatures is largest in the $\mathrm{NH}$ consistent with larger wave driving there (e.g., Shiotani and Hirota 1985);2) the extratropical variance maxima occur during the same season at all levels in the $\mathrm{NH}$, but in the $\mathrm{SH}$ they move from midwinter in the upper stratosphere to spring in the lower stratosphere (e.g., Shiotani et al. 1993); and 3) in the SH the maximum variance is located off the Pole during midwinter, rather than monotonically increasing toward the Pole as in the north (e.g., Scaife et al. 2000). Scaife et al. (2000) noted the presence of a "collar" of increased interannual variability around the South Pole from an analysis of geopotential heights, derived from SSU data. Scaife and James (2000) suggested that the pattern is related to the influence of storm tracks on planetary wave amplitudes near the tropopause, leading to year-to-year changes in stratospheric flow regimes. The October-November SH variance maximum in the MSU-TLS data is likely related to the interannual variability in ozone depletion (e.g., Huck et al. 2005), not accounted for by simple linear detrending.

\section{c. Strength of high-latitude-tropical coupling}

Figure 8 shows the regression of local temperatures onto standardized values of tropical $\left(20^{\circ} \mathrm{S}-20^{\circ} \mathrm{N}\right)$ mean temperatures for the MSU-TLS and SSU-25, -26, and -27 data as a function of calendar month. Shading denotes where the regression coefficients are not significantly different from zero at the $2 \sigma$ level (the number of

FIG. 7. Latitude-month plots of the temporal standard deviation of the (bottom to top) MSU-TLS and SSU-25, -26, and -27 temperature data. The data had the linear trend removed, as a function of latitude and month, prior to the calculation. Note that the contour spacing is $0.25 \mathrm{~K}$ for $0-2 \mathrm{~K}$ and $0.5 \mathrm{~K}$ for $>2 \mathrm{~K}$. 

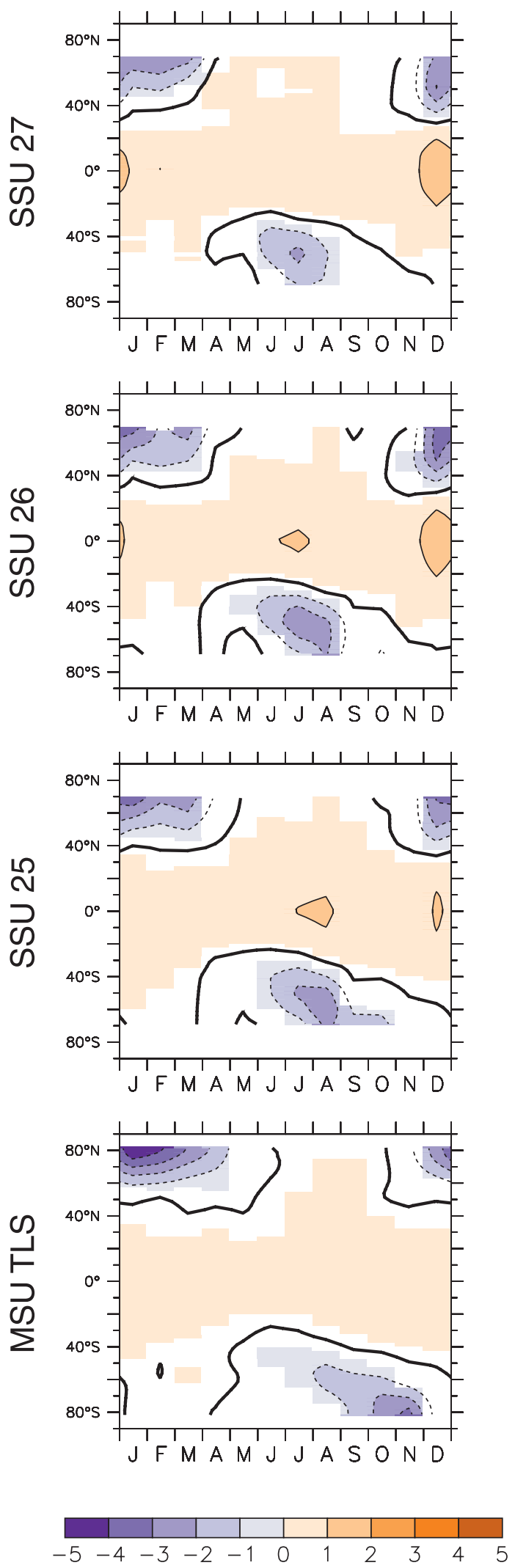

Regression coefficient / K std dev ${ }^{-1}$ independent samples is corrected for autocorrelation as per Santer et al. 2000). As with Fig. 7, the data were detrended as a function of latitude and month prior to the calculation. Note that using a tropical index defined as the $30^{\circ} \mathrm{S}-30^{\circ} \mathrm{N}$ average (i.e., as per Fig. 6) does not noticeably change the results, but the $20^{\circ} \mathrm{S}-20^{\circ} \mathrm{N}$ average was chosen as these latitudes are within the upwelling region calculated by Rosenlof (1995).

The main result in Fig. 8 is that the out-of-phase temperature anomalies characteristic of the BDC extend to all levels in the stratosphere. For all the channels, the results reveal significant and large negative regression coefficients at high latitudes coinciding with the periods of maximum interannual variability shown in Fig. 7 (i.e., hemispheric winter and spring). The negative regression coefficients indicate an out-of-phase relationship, consistent with the signal of the BDC (e.g., cooler tropics corresponding to warmer high latitudes). The magnitudes of the regression coefficients during winterspring are consistent with earlier observations of tropical and high-latitude temperatures in response to stratospheric warming events (Fritz and Soules 1972).

Figure 9 shows analogous results, but for the correlation coefficient $r$ of the local temperature time series against (Fig. 9a) the temperatures averaged poleward of $60^{\circ} \mathrm{N}$, (Fig. 9b) the temperatures averaged poleward of $60^{\circ} \mathrm{S}$, and (Fig. 9c) the tropical temperatures, averaged $20^{\circ} \mathrm{S}-20^{\circ} \mathrm{N}$, by month for the MSU-TLS and SSU data. All correlations are calculated as a function of calendar month. Note that the filled contours indicate where $r$ is significant at the 5\% level. For Fig. 9, a multiple linear regression technique was used on the whole time series to remove the seasonal cycle, linear trend, and solar cycle, via monthly-mean values of the $10.7-\mathrm{cm}$ radio flux (see Garny et al. 2007). The seasonal cycle was modeled with four pairs of cosine-sine harmonics (periods of 12, 6, 4, and 3 months), and seasonal variations in the trend and solar cycle were accounted for with 2 pairs of cosine-sine harmonics (periods of 12 and 6 months), resulting in 18 coefficients overall.

Figure 9 makes clear the out-of-phase relationship between polar and tropical temperatures in the winter and spring seasons associated with the BDC. The general

FIG. 8. Latitude-month plots of the regression coefficient for the local time series of temperature (K; latitude, month) against a normalized tropical average $\left(20^{\circ} \mathrm{S}-20^{\circ} \mathrm{N}\right)$ time series (std dev; month) for the (bottom to top) MSU-TLS and SSU-25, -26, and -27 data. The data had the linear trend removed, as a function of latitude and month, prior to the calculation. The filled contours denote where the regression coefficient is significantly different from zero at the $2 \sigma$ level. 
(a) Correlation with $>60^{\circ} \mathrm{N}$
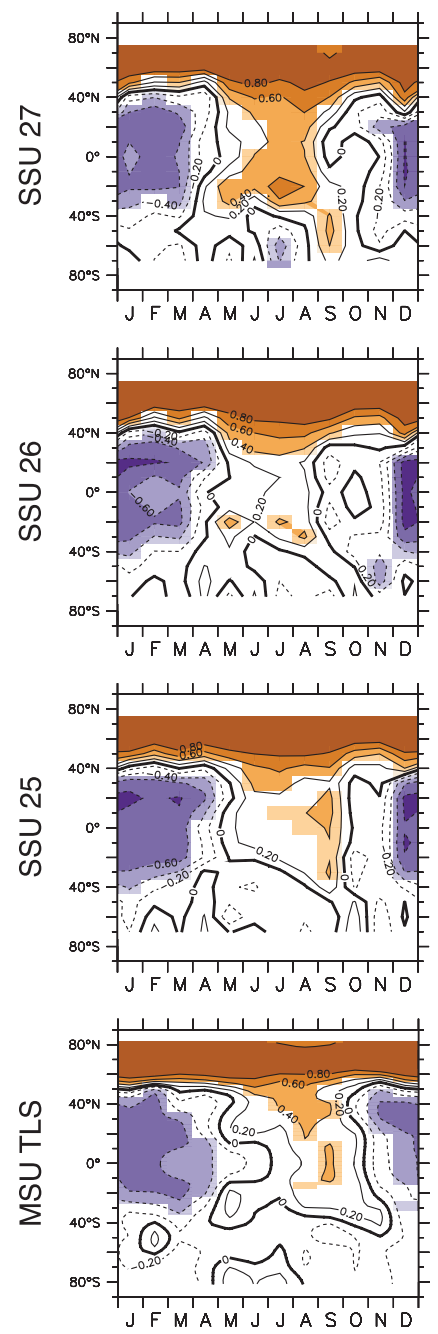

(b) Correlation with $>60^{\circ} \mathrm{S}$
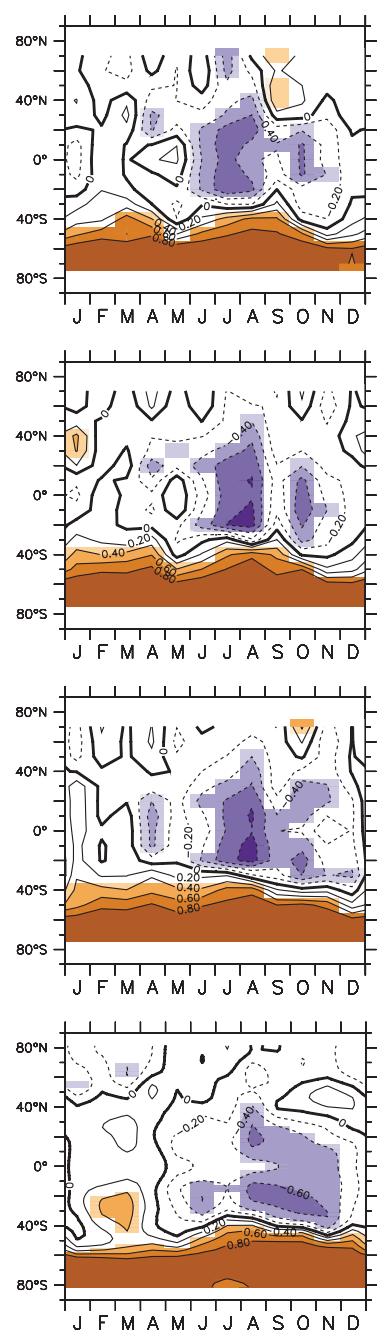

(c) Correlation with $20^{\circ} \mathrm{S}-20^{\circ} \mathrm{N}$
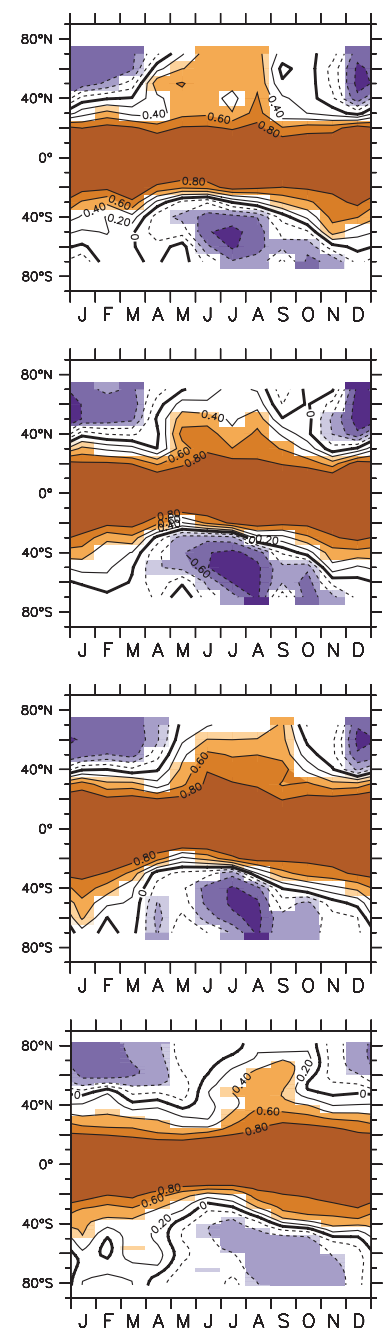

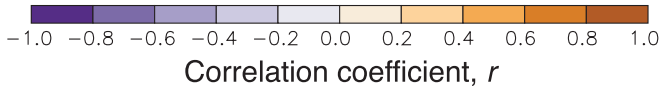

FIG. 9. Latitude-month plots of the correlation coefficient for the time series of local (latitude, month) temperatures with the time series of temperatures averaged (a) $>60^{\circ} \mathrm{N}$, (b) $>60^{\circ} \mathrm{S}$, and (c) $20^{\circ} \mathrm{S}-20^{\circ} \mathrm{N}$, for (bottom to top) the MSU-TLS and SSU-25, -26, and -27 data. The filled contours denote that the correlation is significant at the $5 \%$ level. The data had the linear trend and solar cycle removed prior to the calculation (see text).

structure of the correlations is robust at all levels. Figures 9a,c illustrate that tropical temperatures are out-of-phase with the NH high latitudes from around December to March; Figs. 9b,c illustrate that the tropics are out-ofphase with SH high latitudes from around July to November. All of the periods of significant anticorrelation in the figure coincide with the months of maximum wave driving of the BDC (e.g., Randel et al. 2002). Figure 9c shows that, in all cases, the nodal line for the correlations is located between $\sim 30^{\circ}$ and $50^{\circ}$ latitude, consistent with calculation of the "turnaround latitude" (where $\bar{w}^{*}$ equals zero) by Rosenlof (1995). Figures 9a,b show that the outof-phase temperature response to the winter hemisphere extends into the summer hemisphere, generally $>30^{\circ}$ latitude (see also Tung and Kinnersley 2001).

The out-of-phase relationships revealed in Fig. 9 are clearly evident in the time series of tropical and highlatitude temperatures. Figure 10 shows standardized temperatures for all channels, for the tropics $\left(20^{\circ} \mathrm{S}-20^{\circ} \mathrm{N}\right)$ and (Fig. 10a) $\mathrm{NH}$ high latitudes $\left(>60^{\circ} \mathrm{N}\right)$ in December, and (Fig. 10b) SH high latitudes $\left(>60^{\circ} \mathrm{S}\right)$ in August. The correlations between each pair of tropical and high-latitude 
(a) $>60^{\circ} \mathrm{N}$ and Tropics (Dec)

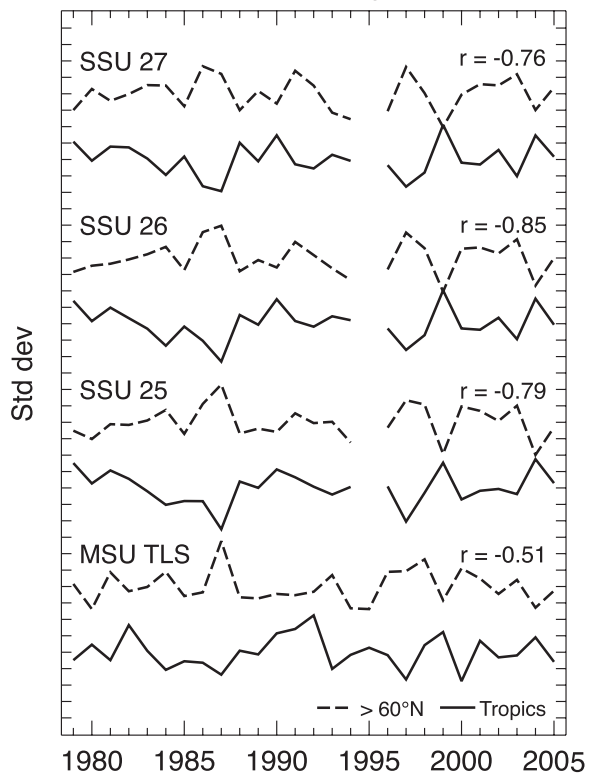

(b) $>60^{\circ} \mathrm{S}$ and Tropics (Aug)

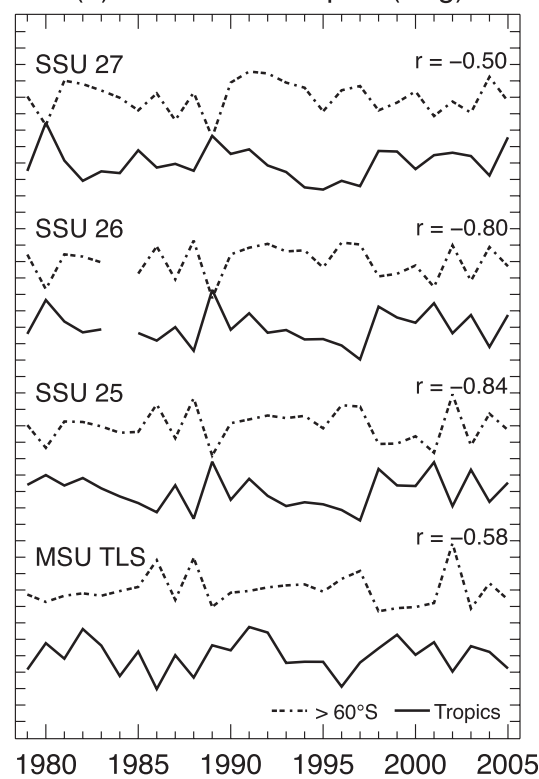

FIG. 10. (a) Time series of the standardized December temperatures for NH high latitudes $\left(>60^{\circ} \mathrm{N}\right)$ and the tropics $\left(20^{\circ} \mathrm{S}-20^{\circ} \mathrm{N}\right)$ for the MSU and SSU data. The value above each pair of lines is their correlation coefficient. (b) As in (a), but for time series of standardized August temperatures for $\mathrm{SH}$ high latitudes $\left(>60^{\circ} \mathrm{S}\right)$ and the tropics. The data had the linear trend removed prior to the calculation.

temperature time series are also shown. Visual inspection of Fig. 10 reveals that peaks and troughs in high-latitude temperatures are matched by opposing troughs and peaks in temperatures from the tropics. Perhaps the most striking example is the 2002 sudden stratospheric warming in the SH (e.g., Newman and Nash 2005), which is pronounced in the MSU-TLS and SSU-25 and -26 high-latitude temperature data, and has a corresponding cold period in the tropics.

The results in Fig. 9 also reveal in-phase correlations between variability in tropical and $\mathrm{NH}$ polar temperatures during NH summer at all levels. These in-phase correlations are only significant for the SSU-27 data, although significant in-phase correlations are present at the same time and location for the other levels if the solar cycle is not removed from the data (not shown).

\section{Conclusions}

The study has presented an analysis of the climatological-mean annual cycle and interannual variability in stratospheric temperatures, with a focus on the tropicalhigh-latitude signals indicative of seasonal and interannual variability in the BDC. The results complement earlier investigations of the signal of the BDC in stratospheric temperatures (e.g., YHW94), as well as existing satellite climatologies of the stratosphere (e.g., Scaife et al. 2000; Randel et al. 2004, and references therein). The primary motivation of the current paper is to exploit the SSU data to extend analysis of the BDC-temperature relationship to cover the depth of the stratosphere.

The climatological-mean annual cycle of zonal-mean temperatures confirms several known features, including the hemispheric asymmetry in high-latitude temperatures (where the SH has both a colder winter and warmer summer than the $\mathrm{NH}$ ), the presence of cold temperatures in the tropical lower stratosphere throughout the year, and the existence of the tropical SAO. The analysis confirms earlier findings of a temperature SAO at higher latitudes, with a small amplitude compared to that of the annual cycle.

Analysis of the annual cycles of global, extratropical, and tropical temperatures of the MSU-TLS data are in agreement with the earlier results of YHW94 but reveal pronounced differences in the seasonal-cycle of global-mean temperatures between lower- and mid-upperstratospheric levels. In the lower stratosphere, tropical and extratropical temperature variations almost cancel to give a near-constant global-mean temperature throughout the year, with the small annual cycle consistent with the seasonal march of tropical ozone concentrations. In the mid- and upper stratosphere, the BDC has a seemingly weaker signature in the seasonal march of temperatures. Here the extratropics are colder than the tropics through most of the year and the seasonal cycle of global-mean temperatures is relatively pronounced. 
The seasonal march in global-mean upper-stratospheric temperatures is at least qualitatively consistent with January-July difference in solar irradiance.

In contrast, the out-of-phase variations in tropical and extratropical temperatures that characterize the BDC are as readily apparent on monthly and interannual time scales in the mid- and upper stratosphere as they are in the lower stratosphere. At all levels, the out-of-phase relationships peak during the seasons of largest wave activity. The results thus suggest that a temperature signal resulting from variations in the strength of the BDC extends throughout the depth of the stratosphere.

Acknowledgments. Remote Sensing Systems are thanked for the provision of MSU data, sponsored by the NOAA/Climate and Global Change Program. (Data are available online at www.remss.com.) Drs. Craig Long and Roger Lin at NOAA/CDC, Bill Randel and Fei Wu at NCAR, and John Nash at the Met Office are all thanked for the provision of, and information pertaining to, the SSU data. Dr. Rolando Garcia is thanked for comments on an earlier draft, and Drs. John Daniel, Bob Portmann, and Eric Ray at NOAA are thanked for helpful comments and suggestions throughout different stages of this analysis. We also thank Prof. Matt Hitchman and two anonymous reviewers for constructive comments that improved our final version.

\section{REFERENCES}

Alexander, M. J., and K. H. Rosenlof, 1996: Nonstationary gravity wave forcing of the stratospheric zonal mean wind. J. Geophys. Res., 101, 23 465-23 474

Andrews, D. G., J. R. Holton, and C. B. Leovy, 1987: Middle Atmosphere Dynamics. Academic Press, 298 pp.

Barnett, J. J., 1974: The mean meridional temperature behaviour of the stratosphere from November 1979 to November 1971 derived from measurements by the Selective Chopper Radiometer on Nimbus IV. Quart. J. Roy. Meteor. Soc., 100, 505-530.

Birner, T., and H. Bönisch, 2011: Residual circulation trajectories and transit times into the extratropical lowermost stratosphere. Atmos. Chem. Phys., 11, 817-827.

Brindley, H. E., A. J. Geer, and J. E. Harries, 1999: Climate variability and trends in SSU radiances: A comparison of model predictions and satellite observations in the middle stratosphere. J. Climate, 12, 3197-3219.

Butchart, N., and Coauthors, 2010: Chemistry-climate model simulations of twenty-first century stratospheric climate and circulation changes. J. Climate, 23, 5349-5374.

Charney, J. G., and P. G. Drazin, 1961: Propagation of planetaryscale disturbances from the lower into the upper-atmosphere. J. Geophys. Res., 66, 83-109.

Delisi, D. P., and T. J. Dunkerton, 1988: Seasonal variation of the semiannual oscillation. J. Atmos. Sci., 45, 2772-2787.

Dunkerton, T., 1978: On the mean meridional mass motions of the stratosphere and mesosphere. J. Atmos. Sci., 35, 23252333.
Fels, S. B., 1985: Radiative-dynamical interactions in the middle atmosphere. Advances in Geophysics, Vol. 28A, Academic Press, 277-300.

Francis, G. L., and M. L. Salby, 2001: Radiative influence of Antarctica on the polar-night vortex. J. Atmos. Sci., 58, 13001309.

Fritz, S., and S. D. Soules, 1970: Large-scale temperature changes in the stratosphere observed from Nimbus III. J. Atmos. Sci., 27, 1091-1097.

, and _-, 1972: Planetary variations of stratospheric temperatures. Mon. Wea. Rev., 100, 582-589.

Fueglistaler, S., A. Dessler, T. J. Dunkerton, I. Folkins, Q. Fu, and P. W. Mote, 2009: Tropical tropopause layer. Rev. Geophys., 47, RG1004, doi:10.1029/2008RG000267.

, P. H. Haynes, and P. M. Forster, 2011: The annual cycle in lower stratospheric temperatures revisited. Atmos. Chem. Phys., 11, 3701-3711.

Gao, X.-H., W.-B. Yu, and J. L. Standford, 1987: Global features of the semiannual oscillation in stratospheric temperature and comparison between seasons and hemispheres. J. Atmos. Sci., 44, 1041-1048.

Garcia, R. R., 1987: On the mean meridional circulation of the atmosphere. J. Atmos. Sci., 44, 3599-3609.

—, and B. Boville, 1994: "Downward control" of the mean meridional circulation and temperature distribution of the polar winter stratosphere. J. Atmos. Sci., 51, 2238-2245.

_ - T. J. Dunkerton, R. S. Lieberman, and R. A. Vincent, 1997: Climatology of the semiannual oscillation of the tropical middle atmosphere. J. Geophys. Res., 102, 26 019-26 032.

Garny, H., G. E. Bodeker, and M. Dameris, 2007: Trends and variability in stratospheric mixing: 1979-2005. Atmos. Chem. Phys., 7, 5611-5624.

Hartmann, D. L., 1976: The structure of the stratosphere in the Southern Hemisphere during late winter 1973 as observed by satellite. J. Atmos. Sci., 33, 1141-1154.

Haynes, P. H., C. J. Marks, M. E. McIntyre, T. G. Shepherd, and K. P. Shine, 1991: On the "downward control" of extratropical diabatic circulations by eddy-induced mean zonal forces. J. Atmos. Sci., 48, 651-678.

Hirota, I., 1978: Equatorial waves in the upper stratosphere and mesosphere in relation to the semiannual oscillation of the zonal wind. J. Atmos. Sci., 35, 714-722.

, 1980: Observational evidence of the semiannual oscillation in the tropical middle atmosphere-A review. Pure Appl. Geophys., 118, 217-238.

—, T. Hirooka, and M. Shiotani, 1983: Upper stratospheric circulations in the two hemispheres observed by satellites. Quart. J. Roy. Meteor. Soc., 109, 443-454.

Hitchman, M. H., and C. B. Leovy, 1986: Evolution of the zonal mean state in the equatorial middle atmosphere during October 1978-May 1979. J. Atmos. Sci., 43, 3159-3176.

— J. C. Gille, C. D. Rogers, and G. Brasseur, 1989: The separated polar winter stratopause: A gravity wave driven climatological feature. J. Atmos. Sci., 46, 410-422.

Holton, J. R., P. H. Haynes, M. E. McIntyre, A. R. Douglass, R. B. Rood, and L. Pfister, 1995: Stratosphere-troposphere exchange. Rev. Geophys., 33, 403-439.

Huck, P. E., A. J. McDonald, G. E. Bodeker, and H. Struthers, 2005: Interannual variability in Antarctic ozone depletion controlled by planetary waves and polar temperature. Geophys. Res. Lett., 32, L13819, doi:10.1029/2005GL022943.

Kanzawa, H., 1989: Warm stratopause in the Antarctic winter. J. Atmos. Sci., 46, 435-438. 
Labitzke, K., 1974: The temperature of the upper stratosphere: Differences between hemispheres. J. Geophys. Res., 79, 21712175.

- 1982: On the interannual variability of the middle stratosphere during the northern winters. J. Meteor. Soc. Japan, 60, 124-139.

Leovy, C., 1964: Simple models of thermally driven mesospheric circulation. J. Atmos. Sci., 21, 327-341.

Logan, J. A., 1999: An analysis of ozonesonde data for the lower stratosphere: Recommendations for testing models. J. Geophys. Res., 104, 16 151-16 170.

McCormick, M. P., L. W. Thomason, and C. R. Trepte, 1995: Atmospheric effects of the Mt. Pinatubo eruption. Nature, 373, 399-404.

McLinden, C. A., S. Tegtmeier, and V. Fioletev, 2009: Technical Note: A SAGE-corrected SBUV zonal-mean ozone data set. Atmos. Chem. Phys., 9, 7963-7972.

Mears, C., and F. J. Wentz, 2009: Construction of the Remote Sensing Systems v3.2 atmospheric temperature records from the MSU and AMSU microwave sounders. J. Atmos. Oceanic Technol., 26, 1040-1056.

Mote, P. W., and Coauthors, 1996: An atmospheric tape recorder: The imprint of tropical tropopause temperatures on stratospheric water vapor. J. Geophys. Res., 101, 3989-4006.

Murgatroyd, R. J., and R. M. Goody, 1958: Sources and sinks of radiative energy from 30 to $90 \mathrm{~km}$. Quart. J. Roy. Meteor. Soc., 84, 225-234.

Newman, P. A., and E. R. Nash, 2005: The unusual Southern Hemisphere stratosphere winter of 2002. J. Atmos. Sci., 62, 614-628.

Perliski, L., and J. London, 1989: Satellite observed long-term averaged seasonal and spatial ozone variations in the stratosphere. Planet. Space Sci., 37, 1509-1525.

_ S. Solomon, and J. London, 1989: On the interpretations of seasonal variations of stratospheric ozone. Planet. Space Sci., 37, 1527-1538

Plumb, R. A., 2002: Stratospheric transport. J. Meteor. Soc. Japan, 80, 793-809.

Randel, W. J., 1988: The seasonal evolution of planetary waves in the southern hemisphere stratosphere and troposphere. Quart. J. Roy. Meteor. Soc., 114, 1385-1409.

— , F. Wu, and R. S. Stolarski, 2002: Changes in column ozone correlated with the stratospheric EP flux. J. Meteor. Soc. Japan, 80, 849-862.

— , and Coauthors, 2004: The SPARC intercomparison of middleatmosphere climatologies. J. Climate, 17, 986-1003.

—, M. Park, F. Wu, and N. Livesey, 2007: A large annual cycle in ozone above the tropical tropopause linked to the BrewerDobson circulation. J. Atmos. Sci., 64, 4479-4488.

_ , R. R. Garcia, and F. Wu, 2008: Dynamical balances and tropical stratospheric upwelling. J. Atmos. Sci., 65, 3584-3595.

— temperature trends. J. Geophys. Res., 114, D02107, doi:10.1029/ 2008JD010421.

Ray, E. A., J. R. Holton, E. F. Fishbien, L. Froidevaux, and J. W. Walters, 1994: The tropical semiannual oscillations in temperature and ozone as observed by the MLS. J. Atmos. Sci., 51, 3045-3052.

, and Coauthors, 2010: Evidence for changes in stratospheric transport and mixing over the past three decades based on multiple data sets and tropical leaky pipe analysis. J. Geophys. Res., 115, D21304, doi:10.1029/2010JD014206.

Reed, R. J., and C. L. Vlcek, 1969: The annual temperature variation in the tropical lower stratosphere. J. Atmos. Sci., 26, 163-167.

Rosenlof, K. H., 1995: Seasonal cycle of the residual mean meridional circulation in the stratosphere. J. Geophys. Res., 100, 5173-5191.

_ 1996: Summer hemisphere differences in temperature and transport in the lower stratosphere. J. Geophys. Res., 101, 19 129-19 136.

_ and J. R. Holton, 1993: Estimates of the stratospheric residual circulation using the downward control principle. J. Geophys. Res., 98, $10465-10479$.

Santer, B. D., T. M. L. Wigley, J. S. Boyle, D. J. Gaffen, J. J. Hnilo, D. Nychka, D. E. Parker, and K. E. Taylor, 2000: Statistical significance of trends and trend differences in layer-average atmospheric temperature time series. J. Geophys. Res., 105, $7337-7356$.

Scaife, A. A., and I. N. James, 2000: Response of the stratosphere to interannual variability of tropospheric planetary waves. Quart. J. Roy. Meteor. Soc., 126, 275-297.

—, J. Austin, N. Butchart, S. Pawson, M. Keil, J. Nash, and I. N. James, 2000: Seasonal and interannual variability of the stratosphere as diagnosed from the UKMO TOVS analyses. Quart. J. Roy. Meteor. Soc., 126, 2585-2604.

Shine, K. P., 1987: The middle atmosphere in the absence of dynamical heat fluxes. Quart. J. Roy. Meteor. Soc., 113, 603-633.

_ - J. J. Barnett, and W. J. Randel, 2008: Temperature trends derived from Stratospheric Sounding Unit radiances: The effect of increasing $\mathrm{CO}_{2}$ on the weighting function. Geophys. Res. Lett., 35, L02710, doi:10.1029/2007GL032218.

Shiotani, M., and I. Hirota, 1985: Planetary wave-mean flow interaction in the stratosphere: A comparison between northern and southern hemispheres. Quart. J. Roy. Meteor. Soc., 111, 309-334.

— N N. Shimoda, and I. Hirota, 1993: Interannual variability of the stratospheric circulation in the southern hemisphere. Quart. J. Roy. Meteor. Soc., 119, 531-546.

Siskind, D. E., S. D. Eckermann, J. P. McCormack, M. J. Alexander, and J. T. Bacmeister, 2003: Hemispheric differences in the temperature of the summertime stratosphere and mesosphere. J. Geophys. Res., 108, 4051, doi:10.1029/2002JD002095.

Solomon, S., 1999: Stratospheric ozone depletion: A review of concepts and history. Rev. Geophys., 37, 275-316.

Tegtmeier, S. V., K. Kruger, I. Wohltmann, K. Schoellhammer, and M. Rex, 2008: Variations of the residual circulation in the northern hemisphere winter. J. Geophys. Res., 113, D16109, doi:10.1029/2007JD009518.

Tung, K. K., and J. S. Kinnersley, 2001: Mechanisms by which extratropical wave forcing in the winter stratosphere induces upwelling in the summer hemisphere. J. Geophys. Res., 106, 22 781-22 791.

Ueyama, R., and J. M. Wallace, 2010: To what extent does highlatitude wave forcing drive tropical upwelling in the BrewerDobson circulation? J. Atmos. Sci., 67, 1232-1246.

van Loon, H., K. Labitzke, and R. L. Jenne, 1972: Half-yearly wave in the stratosphere. J. Geophys. Res., 77, 3846-3855.

Yulaeva, E., J. R. Holton, and J. M. Wallace, 1994: On the cause of the annual cycle in tropical lower-stratospheric temperatures. J. Atmos. Sci., 51, 169-174. 